\title{
ALAT PENYIMPAN ENERGI PANAS MENGGUNAKAN PARAFIN SEBAGAI PCM (PHASE CHANGE MATERIAL) PADA SISTEM PEMANAS AIR SURYA
}

\author{
Ika Yuliyani, Tina Mulya Gantina dan Nurlita Yunikasari \\ Jurusan Teknik Konversi Energi, Politeknik Negeri Bandung \\ E-mail: i_yuliyani@gmail.com; tinapolban@yahoo.co.id; nurlitayunikasari@yahoo.com
}

\begin{abstract}
Abstrak
Energi surya sebagai energi alternatif untuk mememuhi kebutuhan energi merupakan salah satu sumber energi terbarukan. Energi surya dapat dimanfaatkan pada sistem pemanas air, akan tetapi karena energi surya terbatas oleh waktu, maka digunakan penyimpan energi panas berupa PCM (Phase Change Material). Pada penelitian ini PCM yang digunakan adalah jenis parafin. Parafin diletakkan di dalam plat kolektor yang di dalam nya terdapat pipa tempat mengalirnya air yang akan dipanaskan. Sistem kolektor pemanas air yang digunakan adalah plat datar berukuran $110 \mathrm{~cm} \times 60 \mathrm{~cm} \times 8 \mathrm{~cm}$. Karena matahari bersinar terik hanya pada pukul $09.00-16.00$ dengan menggunakan parafin sehagai material penyimpan energi panas dapat mempertahankan temperatur air disaat cuaca mendung atau pada malam hari (pukul 16.00 - 18.00). Sehingga apabila material penyimpan energi panas ini dapat bekerja dengan baik, maka dapat diperoleh air panas di saat matahari tidak bersinar terik atau sudah terbenam. Hasil pengujian menunjukkan efisiensi pemanas air yang menggunakan parafin adalah sebesar 52,29\%, sedangkan yang tidak menggunakan parafin sebesar 47,42\%.
\end{abstract}

Kata kunci : Energi surya, PCM, Parafin, Pemanas air tenaga surya plat datar

\begin{abstract}
Solar energy as an alternative energy to meet energy needs is one of renewable energy source. Solar energy can be utilized in water heating systems, but hecause solar energy is not continue system through the time, then we used PCM (Phase Change Material) to store the heat. In this research, we use paraffin as PCM. Paraffin was placed in the absorber plate and we also placed pipe for water flow that will be heated. This water heater have size $110 \mathrm{~cm} x$ $60 \mathrm{~cm} \times 8 \mathrm{~cm}$. Because solar only reach it's energy peak on $09.00-16.00$, by using paraffin as a heat storage, the water temperature could be stable whenthe weather is bad or on the night (when it is 16.00-18.00). If the heat storage could work well, then we could get water heater when the weather is bad or on the night. The test results show, efficiency of this solar water heater by using paraffin is $52,29 \%$, while the efficiency of solar water heater with no paraffin is $47,42 \%$.
\end{abstract}

Keywords: Solar energy, PCM, Paraffin, Flat plate solar water heater

\section{PENDAHULUAN}

Salah satu pemanfaatan radiasi surya adalah pada pemanas air energi surya. Namun pemanfaatan radiasi surya pada pemanas air memiliki beberapa kelemahan, yaitu proses pemanasan air akan terganggu jika cuaca mendung dan tidak dapat digunakan pada malam hari, sehingga sulit untuk mempertahankan energi panas yang diterima oleh pemanas air energi surya tersebut. Untuk membantu mengatasi permasalahan di atas, maka sistem pemanas air perlu dilengkapi dengan media penyimpan panas. Salah satu penyimpan panas adalah material berubah fasa (PCM). Pada siang hari panas yang diterima air dari radiasi surya diserap oleh PCM yang mengakibatkan PCM 
berubah fasa. Sedangkan pada saat radiasi surya menurun karena cuaca mendung atau saat malam hari mengakibatkan temperatur air menurun, maka PCM akan melepaskan kembali panas ke air yang akan membuat temperatur air dapat dijaga konstan[1].

Tujuan dari penelitian ini adalah dihasilkannya media penyimpan energi panas untuk pemanas air surya, dan untuk mengetahui kinerja dari alat penyimpan energi panas tersebut.

\section{TINJAUAN PUSTAKA}

Radiasi matahari merupakan suatu bentuk radiasi termal. Matahari dengan diameter $1,39 \times 10^{9} \mathrm{~m}$ dan suhu pada permukaan matahari $5762 \mathrm{~K}$, serta jarak rata-rata antara matahari dan bumi sebesar $1,5 \times 10^{11} \mathrm{~m}$, maka besarnya fluks radiasi matahari untuk setiap satuan luas dengan arah radiasi yang tegak lurus tepat di luar atmosfer bumi adalah [2]:

$\mathrm{G}=\frac{\sigma d s^{2} T s^{4}}{4 \mathrm{R}^{2}}$

Konduksi adalah proses transfer energi panas karena partikel-partikel dalam benda tersebut bertumbukkan. Konduksi Panas terjadi karena adanya perbedaan temperatur. Panas mengalir dari bagian yang bertemperatur tinggi ke bagian yang bertemperatur rendah dengan medium padat, cair atau gas. Laju perpindahan panas konduksi dinyatakan dengan Hukum Fourrier [2].

$\mathrm{qk}=-\mathrm{k} \cdot \mathrm{A} \cdot \mathrm{dTdx}$

Konveksi terjadi apabila panas bergerak dari satu bagian ke bagian lain dengan medium fluida. Konveksi terjadi akibat dari perubahan panas jenisnya yang berekspansi pada bagian fluida yang dipanaskan.

$\mathrm{qc}=$ hc. $\mathrm{A} \cdot \Delta \mathrm{T}$

Radiasi adalah perpindahan kalor oleh gas foton yang dapat mengalir dari satu bagian ke bagian yang lain. Perpindahan kalor secara radiasi pada hakekatnya proses terjadi dengan perantaraan foton dan gelombang elektromagnet. Proses perpindahan kalor secara radiasi tidak terjadi dibagian dalam bahan akan tetapi pada permukaan bahan. Apabila sejumlah kalor dari radiasi energi menimpa suatu permukaan maka sebagian akan dipantulkan, sebagian akan diserap dalam bahan, dan sebagian bahan akan menembusi bahan dilanjutkan ke luar[3].

$\mathrm{qr}=\varepsilon \sigma \mathrm{A}\left(\mathrm{T}_{1}^{4}-\mathrm{T}_{2}^{4}\right)$

Sistem pemanas air surya aktif merupakan sistem yang menggunakan bantuan pompa untuk mensirkulasikan air di dalam kolektor, dimana sistem pemanas air surya aktif ini terdiri dari kolektor, pompa sekunder, tangki penyimpan, heater, dan pipa-pipa.

Sistem pemanas air surya pasif adalah sistem pemanas air yang berlangsung secara alami, tidak dengan menggunakan pompa sirkulasi. Sirkulasi fluida alami ini disebabkan karena perbedaan massa jenis air antara air yang keluar dari kolektor dengan air yang masuk kolektor.

Klasifikasi PCM seperti terlihat pada diagram di bawah ini [4]:

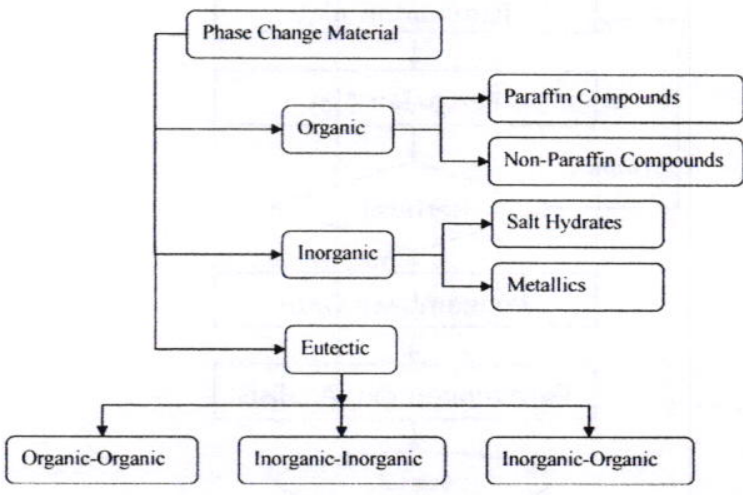

Gambar 1. Klasifikasi PCM

Parafin merupakan material yang dapat digunakan sebagai material penyimpan energi panas. Parafin memiliki dengan karakteristik termofisik sebagai berikut :
a. Titik leleh
$=42{ }^{\circ} \mathrm{C}-62^{\circ} \mathrm{C}$
b. Cp padat
$=2200 \mathrm{~J} / \mathrm{kg}^{0} \mathrm{C}$
c. Cp cair
$=2150 \mathrm{~J} / \mathrm{kg}^{0} \mathrm{C}$
d. Kalor laten
$=178 \mathrm{~kJ} / \mathrm{kg}$
e. ppadat
$=910 \mathrm{~kg} / \mathrm{m}^{3}$
f. pcair
$=790 \mathrm{~kg} / \mathrm{m}^{3}$

Efisiensi dari pemanas air surya dapat didefinisikan sebagai perbandingan antara energi 
panas yang berguna dari kolektor dengan intensitas dari radiasi surya.

$\eta=\frac{\mathrm{m} \times \mathrm{Cp} \times(\mathrm{To}-\mathrm{Ti})}{\operatorname{Ak} \times\left(\frac{\mathrm{lk}}{\mathrm{t}}\right)}$

\section{METODOLOGI}

Diagram alir pembuatan alat merupakan diagram alir yang berisi langkah-langkah yang dilakukan untuk pembuatan alat mulai dari perancangan alat sampai pada pengambilan dan analisia data. Langkah-langkah tersebut seperti pada diagram alir berikut.

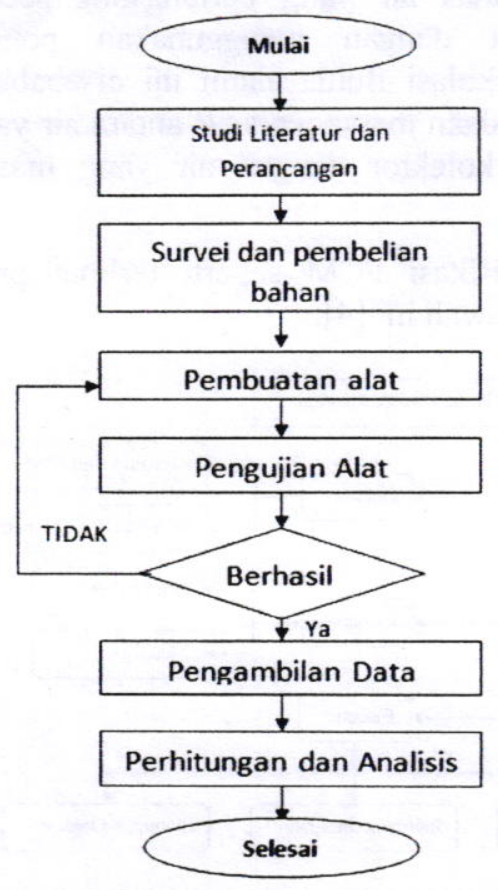

Gambar 2. Diagram alir pembuatan alat

\section{Desain Alat}

Untuk menghitung luas kolektor digunakan rumus seperti berikut [5][6]:

$\mathrm{Ak}=\frac{\mathrm{q}}{\operatorname{Ir} \times \eta}$

Dengan debit air (Q) yang diinginkan adalah sebesar $1,042 \times 10^{-6} \mathrm{~m}^{3} / \mathrm{s}, \rho$ air pada temperatur standar adalah $997,1 \mathrm{~kg} / \mathrm{m}^{3}$, radiasi matahari sebesar $600 \mathrm{~W} / \mathrm{m}^{2}$, dan efisiensi sebesar $45 \%$, maka diperoleh $\mathrm{Ak}=0,322 \mathrm{~m}^{2}$.
Untuk menghitung panjang pipa yang dibutuhkan digunakan rumus seperti berikut :

$\mathrm{Al}=\Pi \times \mathrm{D} \times \mathrm{L}=\frac{\mathrm{m} x C p \times \Delta T}{I r}$

Dengan diameter pipa sebesar $1 / 4$ inch, maka diperoleh panjang pipa sebesar $7,75 \mathrm{~m}$.

Banyaknya parafin yang akan digunakan untuk menyimpan energi panas pada pemanas air surya ini adalah sebanyak $9,6 \mathrm{~kg}$.

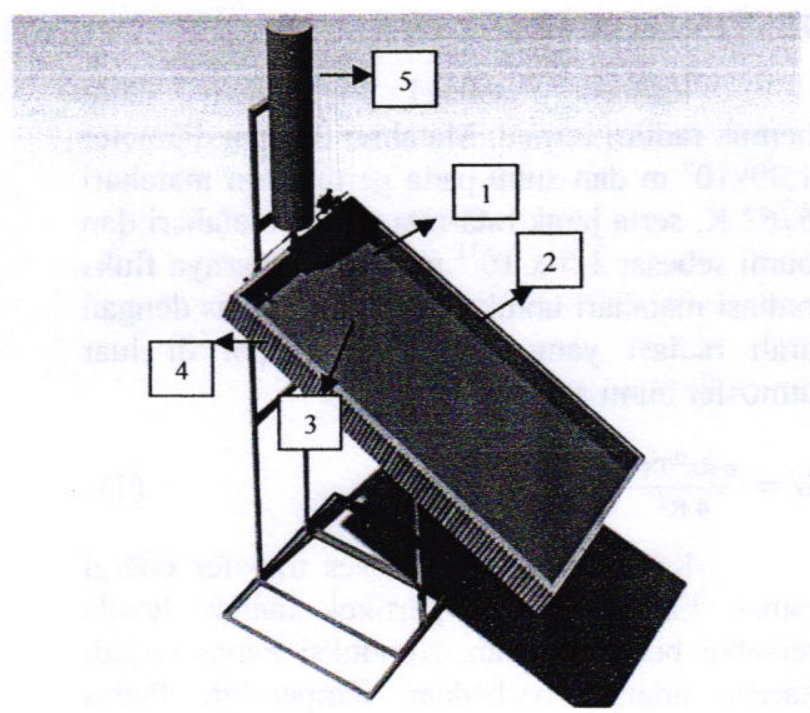

Gambar 3. Kolektor pemanas air tenaga surya

Keterarangan :

$1=$ Plat absorber

$2=$ Kaca

$3=$ Papan kayu

$4=$ Rangka

$5=$ Tangki air masuk

Langkah-langkah pengujian alat penyimpan energi panas untuk sistem pemanas air surya adalah sebagai berikut :

1. Persiapkan alat, yaitu kolektor dan alat ukur.

2. İsi tangki air masuk sampai penuh.

3. Atur laju alir air, dengan menggunakan bukaan katup. Jaga agar tetap konstan.

4. Ukurlah parameter-parameter setiap 10 menit sekali. 


\section{HASIL DAN PEMBAHASAN}

Pengujian dilakukan dua kali, yaitu pada pemanas air surya tanpa parafin dan pemanas air surya dengan menggunakan parafin.

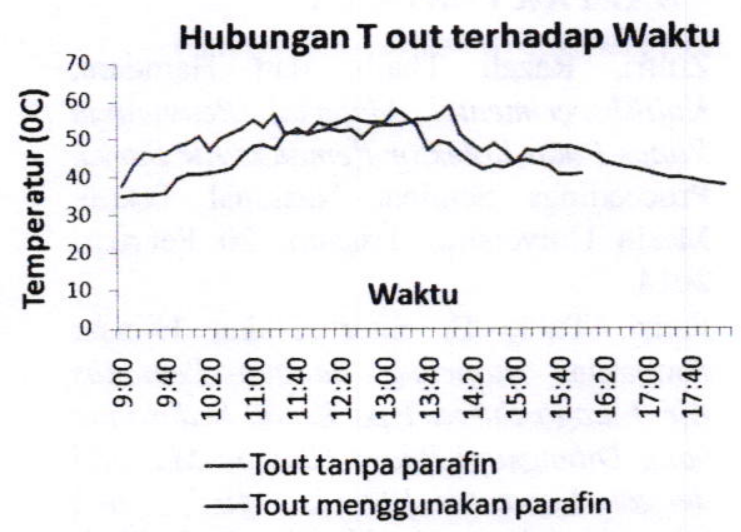

Gambar 4. Hubungan T out terhadap waktu

Gambar 4 menunjukan perbedaan antara temperatur air keluar kolektor pada alat pemanas air yang tidak menggunakan penyimpan energi panas dengan yang menggunakan penyimpan energi panas. Dapat dilihat bahwa temperatur air keluar kolektor tanpa menggunakan parafin hanya bisa memanaskan air pada saat ada matahari yaitu pada pukul 09.00 sampai dengan pukul 16.00. Sedangkan dengan menggunakan parafin temperatur air keluar kolektor dapat dipertahankan dari mulai pukul 09.00 sampai dengan pukul 18.10.hal tersebut membuktikan bahwa parafin dapat mempertahankan panas air sampai dengan 2 jam.

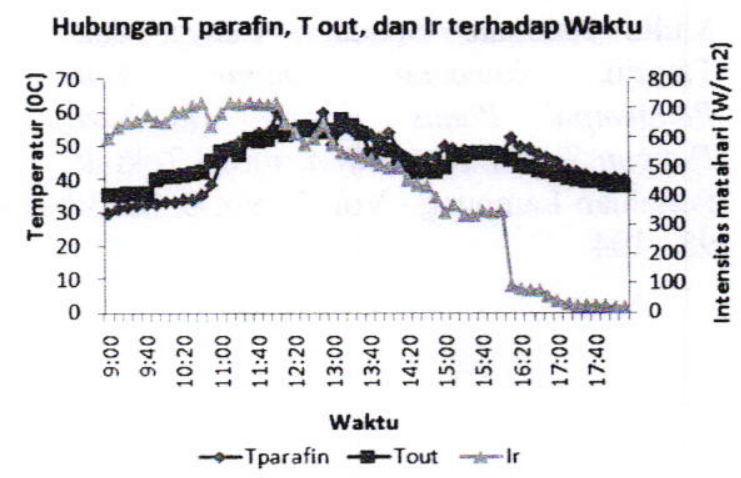

Gambar 5. Hubungan T parafin, T out, dan Ir terhadap waktu
Dari gambar 5 dapat dilihat bahwa temperatur air meningkat beriringan dengan meningkatnya intensitas matahari.Tetapi setelah pukul 12.00-18.00 intensitas matahari menurun, sehingga air dalam pipa kolektor dipanaskan oleh parafin.Selain parafin, temperatur plat dan temperatur kaca ikut mempertahankan temperatur air panas yang dihasilkan.Karena para saat intensitas matahari menurun, plat dan kaca masih memiliki temperatur sebesar $40^{\circ} \mathrm{C}$.Temperatur parafin menggantikan panas dari matahari.Temperatur parafin tidak berbeda jauh dengan temperatur air keluar kolektor.Parafin memberikan panas kepada pipa kolektor disaat berubah fasa dari lelehan menjadi padat, yaitu disaat temperatur parafin dibawah $42^{\circ} \mathrm{C}$.

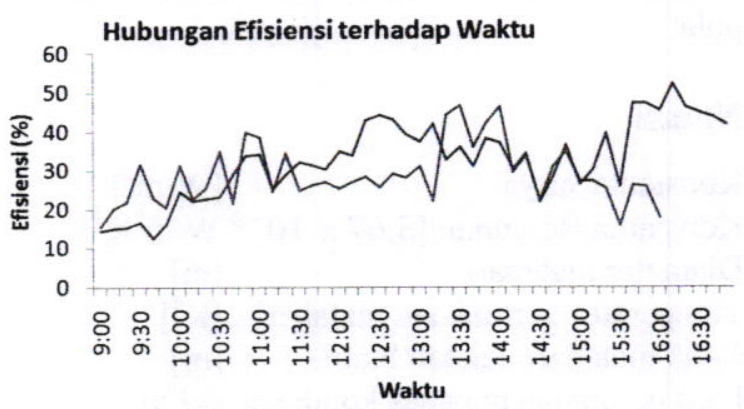

Gambar 6. Hubungan efisiensi terhadap waktu

Gambar 6 menunjukkan perbandingan efisiensi alat, dengan garis merah merupakan efisiensi alat menggunakan parafin dan garis biru merupakan efisiensi alat tanpa parafin. Nilai efisiensi tertinggi pada alat pemanas air tanpa menggunakan parafin adalah 47,42 \% yang terjadi pada pukul 13.30. Sedangkan efisiensi terendah adalah sebesar $15,9 \%$ yang terjadi pada pukul 09.00. Untuk pemanas air dengan menggunakan parafin efisiensi terbesar adalah sebesar 52,29\% yang terjadi pada pukul 16.10 , sedangkan temperatur terendah adalah sebesar $12,9 \%$ yaitu pada pukul 09.40. Secara keseluruhan nilai efisiensi dengan menggunakan parafin lebih besar dari yang tidak menggunakan parafin. Hal ini dikarenakan, dengan menggunakan parafin panas didapat tidak dari 
matahari saja, tetapi panas pun didapat dari parafin.

\section{KESIMPULAN}

Dari percobaan yang telah dilakukan, maka dapat disimpulkan :

1. Efisiensi terbesar pemanas air tanpa menggunakan parafin adalah sebesar 47,42 $\%$, sedangkan efisiensi terbesar pemanas air dengan menggunakan parafin adalah sebesar $52,29 \%$.

2. Pemanas air yang menggunakan parafin dapat mempertahankan panas 2 jam lebih lama dibandingkan dengan pemanas air yang tidak menggunakan parafin.

3. Efisiensi dipengaruhi oleh nilai intensitas matahari, temperatur air masuk, dan temperatur air keluar. Semakin baik nilai ketiganya maka efisiensi akan lebih baik pula.

\section{Notasi}

\begin{tabular}{|c|c|c|}
\hline G & Konstanta surya & {$\left[\mathrm{W} / \mathrm{m}^{2}\right]$} \\
\hline$\sigma$ & Konstanta Boltzman $\left[5,67 \times 10^{-8}\right.$ & $\left.{ }^{8} \mathrm{~W} / \mathrm{m}^{2} \mathrm{~K}^{4}\right]$ \\
\hline ds & Diameter matahari & {$[\mathrm{m}]$} \\
\hline Ts & Temperatur permukaan matahari & {$\left[\mathrm{K}^{4}\right]$} \\
\hline $\mathrm{R}$ & Jarak matahari dengan bumi & {$[\mathrm{m}]$} \\
\hline qk & Laju perpindahan panas konduksi & {$[\mathrm{kJ} / \mathrm{s}]$} \\
\hline k & Konduktivitas termal bahan & {$\left[\mathrm{W} / \mathrm{m} .{ }^{0} \mathrm{C}\right]$} \\
\hline A & Luas penampang & {$\left[\mathrm{m}^{2}\right]$} \\
\hline & Laju perpindahan panas konveksi & {$[\mathrm{kJ} / \mathrm{s}]$} \\
\hline h & Koefisien konveksi & $\mathrm{W} / \mathrm{m}^{2} .{ }^{0} \mathrm{Cl}$ \\
\hline $\mathrm{q}$ & Laju perpindahan kalor radiasi & {$[\mathrm{W}]$} \\
\hline & Emisivitas benda & \\
\hline$\Delta$ & Perubahan temperatur & {$\left[{ }^{0} \mathrm{C}\right]$} \\
\hline$\dot{m}$ & Laju alir massa air & {$[\mathrm{kg} / \mathrm{s}]$} \\
\hline 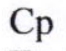 & Kapasitas kalor & {$\left[\mathrm{kJ} / \mathrm{kg}^{0} \mathrm{C}\right]$} \\
\hline . & Temperatur air output & {$\left[{ }^{0} \mathrm{C}\right]$} \\
\hline $\mathrm{Ti}$ & Temperatur air input & {$\left[{ }^{0} \mathrm{C}\right]$} \\
\hline & Luas kolektor & {$\left[\mathrm{m}^{2}\right]$} \\
\hline & Pancaran radiasi matahari & {$\left[\mathrm{kWh} / \mathrm{m}^{2}\right]$} \\
\hline
\end{tabular}

$\begin{array}{lll}\text { Ir } & \text { Intensitas radiasi matahari } & {\left[\mathrm{W} / \mathrm{m}^{2}\right]} \\ \rho & \text { Massa jenis air } & {\left[\mathrm{kg} / \mathrm{m}^{3}\right]} \\ \eta & \text { Efisiensi } & {[\%]}\end{array}$

\section{DAFTAR PUSTAKA}

[1] Zulfri, Razali Thaib, dan Hamdani, KajiEksperimental Material Penyimpan Panas Pada Kolektor Pemanas Air Surya, Proceedings Seminar Nasional Teknik Mesin Universitas Trisakti, 20 Februari 2014

[2] Fauzi, Tulus B. Sitorus, dan Himsar Ambarita, "Rancang Bangun Pemanas Air Tenaga Surya Tipe Kotak Sederhana yang Dilengkapi Phase Change Material dengan Kapasitas 100 Liter Air", Jurnal Dinamis,Volume I, No.11, Juni 2012 ISSN 0216-7492

[3] Holman, J.P. 1986. Heat Transfer Sixth Edition. Penerbit : McGraw-Hill Book Company.

[4] Lalit M. Bal, Santosh Satya dan S.N. Naik, "Solar dryer with thermal energy storage systems for drying agricultural food products: A review", Renewable and Sustainable Energy Reviews 14 (2010), Elsevier,pp: 2298-2314

[5] Jufrizal, Farel H. Napitupulu, dan Himsar Ambarita, Studi Eksperimental Performansi Solar Water Heater Jenis Kolektor Plat Datar dengan Penambahan Thermal Energy Storage, Jurnal Ilmiah Teknik Mesin Cylinder, Vol. 1 No. 2, October 2014: 27-36

[6] Mulia Rahman, Budianto Lanya, dan Tamrin, Rancang Bangun Alat Pengumpul Panas Energi Matahari Dengan Sistem Termosifon, Jurnal Teknik Pertanian Lampung- Vol. 2, No. 2, 2013: $95-104$ 